Chris Garcia, University of New Mexico

Ariana Julian, University of California, Davis

Susan Kay, Miami University, Ohio Gary Klass, Illinois State University

Gus Koehler, California Research Bureau

Steven Kelman, Harvard University (on leave, working in the government)

Norman Luttberg, Texas A\&M University

Albert Matheny, University of Florida

Melinda Mueller, Eastern Illinois University

Gary Nederman, University of Arizona

Vincent K. Pollard, University of

Hawaii (Ph.D. candidate)

David Rausch, Fairmont State College
Mark Rush, Washington and Lee University

Steffen Schmidt, Iowa State University

Aron Tannenbaum, Clemson University

Jean Torcum, California State University, Sacramento

Elliot Vittes, University of Central Florida

Matthew Wetstein, California State University, Stanislaus

Oliver H. Woshinsky, University of Southern Maine

My apologies to those whose comments I missed or received after this piece was written. Please send me your observations so that $I$ can be sure to include them in the next issue. $P S$ welcomes essays with additional analysis and commentary.

\section{References}

Astin, Alexander W., et al. The American College Freshman: National Norms, the annual studies for fall 1986 through 1994. 1986-1994, inclusive. Los Angeles: Higher Education Research Institute, UCLA.

Dey, Eric L., Alexander W. Astin, and William S. Korn. 1991. The American Freshman: Twenty-Five Year Trends, 19661990. Los Angeles: Higher Education Research Institute, UCLA.

Sax, L. J., A. W. Astin, W. S. Korn and K. M. Mahoney. 1995. The American Freshman: National Norms for Fall, 1995. Los Angeles: Higher Education Research Institute, UCLA.

\title{
The Challenge of Campaign Watching: Seven Lessons of Participant-Observation Research'1
}

\author{
James M. Glaser, Tufts University
}

$\mathbf{W}_{\text {hen }}$ the term "participant-observation" comes up, many political scientists immediately think of Richard Fenno. Indeed, Fenno's description of his work as "soaking and poking" has become synonymous with this style of research. When I sought to do research based on participant-observation techniques, it was natural to turn to Fenno and, quite fortuitously, he gave a series of lectures at the University of California, Berkeley, where I was a graduate student, just as I was preparing to do research for my doctoral dissertation. In his talks, which were later published as a book (Fenno 1990), he spoke of some of the problems and difficulties of participant-observation work. His comments were invaluable to me as I prepared to visit Mississippi and Alabama to do my initial fieldwork.

While my notes from his talks were dogeared and weathered by the end of that year, there were times when even my "bible" could not help me. I encountered new problems and fresh issues because my task was basically different. Like Fenno, I was studying congressional politics but, unlike him, I was examining campaigns, not politicians.

This difference had important consequences. It meant that rather than doing research both in and out of campaign season, I did my work in that crazy period of time right before an election. While Fenno spent intensive amounts of time travelling districts and states with one congressional incumbent and eschewed covering opponents, I tried to interview and spend time with competing candidates as they battled for an open seat. Fenno could assure politicians that "within the scope of their political world, [he] recognized a single loyalty-to them" (72). I could not.

Much of Fenno's general advice on conducting interviews, developing rapport, and keeping intellectual distance was still relevant to me. Nonetheless, another set of rules applied to my research. I was going to have to make my own mistakes-and plenty of them-as I learned to be an effective participant-observer in a different setting.

My project involved an intensive study of six special congressional elections held between 1980 to 1993 (three of which were witnessed first-hand, three of which were reconstructed through newspaper clippings and extensive interviews). In witnessing elections, I spent several weeks following candidates, and going to debates, rallies, com- mercial tapings, church services, meetings with volunteers, press conferences, prayer breakfasts, and any other events I could manage to get into. I also interviewed actors in the drama-candidates, their campaign managers and media consultants, national party officials and local party volunteers, ministers and labor leaders, print and broadcast journalists, and whoever else I could get to talk with me. The results, I hope, are more than just reports of campaign dialogue, but more detailed depictions of the contests.

Such depictions can have much value. Many political scientists study elections and electoral behavior at their computers. While there is certainly nothing wrong with doing this (I do it too), to draw conclusions about electoral results or electoral behavior also requires some understanding of the context in which elections take place. As Herbert Simon (1985) writes, "To understand political choices, we need to understand where the frame of reference for the actors' thinking comes from-how it is evoked. An important component of the frame of reference is the set of alternatives that are given consideration in the choice process. We need to understand not only 
how people reason about alternatives, but where the alternatives come from in the first place" (302).

By presenting detailed case studies of how partisan alternatives are formed and presented to the voter, one sets up political analysis, tests prevailing assumptions, and suggests solutions to analytical problems, if not always providing definitive answers. There is no doubt that the material to fill these case studies is best gathered in the field where one can easily take note of the minutiae of political strategy, talk with a variety of political actors as they are engaged in political activity, and get a real sense of the setting in which political competition is taking place. Events past can be reconstructed from others' reports, but there is no substitute for being there.

In my own work, I hope that my case studies shed some light on the resolution to two puzzles of the southern realignment. First, if racial issues were such a boon to $\mathrm{Re}$ publicans, how did Democratic congressional candidates-especially candidates for open seatskeep winning through the 1970 s, 1980s, and early 1990s? Second, if Ronald Reagan and George Bush swept the South every four years, how were Democrats able to hold on to congressional seats throughout their tenures? While things continue to look ever more promising for southern Republicans, the reasons behind the long-delayed realignment are fascinating. That story and my broader argument about race and politics in the region are fully developed elsewhere (Glaser 1996). My purpose here is to lay out some of the mistakes I made and some of the lessons I learned covering dueling campaigns in the final frenzied weeks and days before congressional elections. It is true that most of these lessons are specific to this situation. I believe, however, that they also may be relevant to others doing participantobservation research in highly charged political settings.

Schedule strategically. Before I went to Alabama for my first experience in the field, I worried about making complete use of the 11 days
I had to spend there. I set up interviews before I went, some in places very far apart, and I contacted people who I thought would be important to see. Once there, however, I found myself constrained by my schedule. On one occasion, I had to skip an important event because of an arranged interview with a peripheral subject (who forgot about our appointment and did not show). On another, I lost the chance to ride in the car with one of the candidates, an opportunity that came up spontaneously. By being overscheduled, I lost flexibility when such opportunities arose. Moreover, as many campaign decisions are made on short notice and as schedules are constantly in flux, I discovered that I needed to be able to respond to sudden turns of events. The more I did this kind of research, the more confidence I gained that I could schedule more effectively once in the field.

This is not to say that one should avoid making appointments. I found it best to set up some interviews for my first few days in the district, particularly with campaign officials, and to leave my remaining time flexible and free. In this, I was borrowing from a common research practice, "snowballing"-using an interview to get other interviews by asking a subject who else might be useful to talk with and even using their name to make the connection. Successful interviews also snowballed into invitations to various events.

A good interview made the campaigns aware of me and my project. It gave me credibility. And, it was held when my subjects had events to invite me to. As campaign schedules are rarely fixed for more than a day or two, even for something as big as a presidential visit, calling a week ahead to find out about events is not the way to proceed. Planning day-to-day is more effective. Often, at the end of an interview, I was invited to an event that evening or the next day.

Adjust the interview request to the situation. Whatever the challenges of arranging and conducting interviews, they are more difficult dur- ing a campaign. Studying campaigns in the field means dealing with people engaged in all-consuming tasks in a hurried environment. They rarely return the first phone call nor have much time to speak with an outsider. They often are moving from one event to the next.

Arranging to meet with people involved in a campaign thus calls for ingenuity and flexibility. It is always the case that the interviewer must accommodate the schedule and rules set up by the respondent. Typically, there are expectations of how, where, and how long an interview will be conducted. On the campaign trail, these expectations no longer govern, and the researcher must go further to accommodate the respondent and to get the interview. I found that two different approaches made people more amenable to speaking with me.

First, it was often useful to ask for a brief interview during the campaign and for a more extensive one later, either over the telephone or in person. To get people to talk with me, I wanted to be persistent, but not aggressive, and this was one way to strike this balance. Many people had difficulty rejecting my modest request. But it was more than this. Conducting a short interview during the campaign and a long interview later had other advantages, and not only for my subjects. This solution had the virtue of allowing me to talk with people after the heat of the battle when they were often more candid and less wary than in our first meetings. They also had a little bit of distance from events and were able to comment on them with more perspective. What started as something I did out of necessity became a practice I came to prefer.

Of course, sometimes it was difficult to pin busy people down after the election. In one instance, the campaign aide of a winning candidate refused to return my repeated requests to arrange an interview with the new congressman. After a dozen phone calls, I gave up. Four years later, out of the blue, the congressman himself called me back, perhaps setting some kind of record for returning a phone call. 
We ultimately met and have now established a relationship.

It also happens that the request for a short interview provides a foot in the door and that, occasionally, the brief interview will turn into a longer, more productive one. Anyone who has conducted interviews will find that resistance often fades as many subjects enjoy offering their opinions and telling their tales. In one case, I had a campaign manager gruffly tell me that he only had a few minutes to talk. Once we got started and he could sense that I knew something about the campaign and about Alabama politics, he put down his guard and put up his feet. After answering my questions for about three quarters of an hour, he began regaling me with "war stories."

A second approach to arranging interviews during the campaign is to use the travel time between campaign events, otherwise dead time that is often ideal for talking with people. I found that conversations in the car were often less guarded, and that some of the most interesting revelations came out in transit. In some cases, this meant offering someone a ride to a series of events. Providing rides had the additional benefit of helping me find my way more easily as my companions were often familiar with the various towns and streets we were travelling.

More often, travelling with a subject meant taking up their offer of a ride. This situation had many of the same benefits as serving as the driver, but it also had a couple of drawbacks. I spent one car ride with a very distracted campaign manager riding 90 miles an hour on 2-lane country roads. I was not surprised to learn that he drove off a bridge on election night. Fortunately, he was not badly hurt, and, thankfully, I was not with him.

Riding with a subject also put me at the mercy of someone else's schedule. On one occasion, it put me several hours away from my car at the end of the day. Yet, travelling with a candidate or with campaign staff enabled me to observe scenes I would not otherwise have witnessed. It gave me the chance to hear post-mortem analyses of events, something that added an interesting perspective to my own observations. Best of all, the ride home was a time when people were free with their opinions and in a relaxed mood. In one instance, it took 45 minutes to get to an event, but two hours to get home as the driver (a campaign manager) enjoyed plying me with his opinions and stories.

Get multiple perspectives. Setting up interviews with political actors outside the campaigns, such as journalists, community leaders, preachers, and party officials, is easier and less intimidating than making arrangements with those in the campaigns. These people have a connection to the events playing out, but they are not so restricted by them as candidates and their staff. I found that they had more time to offer, were less wary of my intentions, and had access to information about the campaigns that the campaign staff would never have given me. And getting their perspective on events was no less important to me.

My research strategy was loosely borrowed from the movie Rashomon by Japanese filmmaker Akira Kurosawa. In this movie, Kurosawa tells the story of a bandit's attack on a couple in the Japanese countryside. The genius of the film is that the same story is told from the four separate perspectives of the murdered man, his wife, the attacker, and a bystander. The four stories are surprisingly different, but together they work to create the whole account. No one of the stories is objective in that all four characters have limited perspectives and strong biases (even the bystander, who takes a weapon from the scene after the murder, becomes involved in the event). Their biases are part of the story, however, and between them, Kurosawa collects the important detail. Even the contradictory detail is worth noting.

Likewise, by putting together the perspectives of a variety of people, and people tangentially involved in the election as well as those immediately involved, I was able to make the whole picture sharper.
Like the characters in the film, each person carried a different view of events, not just because of their political biases, but because of their political roles. Collecting and sometimes reconciling these views (and adding eyewitness observations) allowed me to piece together a comprehensive and fair recounting of events.

Recognize that establishing trust and gaining access are goals sometimes at odds with each other. Gaining access to campaign events or to the inner workings of a campaign is not an easy task, particularly given the cloak and dagger mentality that pervades many of them. It would seem that campaigns would cooperate with those they trust, that this would be the most important factor. But cooperation from a campaign also depends on how important the researcher is to the campaign or the candidate.

Herein lies a dilemma for the social scientist for, unfortunately, those outside actors who are perceived to be important to the campaign are often not trusted. Take journalists, for instance. Journalists are important to the campaigns, and campaign staff try to keep them informed on events and to meet their requirements. How the campaign is reported in the newspapers or on television has great bearing on the election. Thus, campaigns often provide journalists with lots of information but offer only selective access and work hard to control the information.

Given my purposes, and my intent to observe competing campaigns, two things seemed to matter. First, my subjects were receptive to the fact that I was writing a book and that they would be characters in it. The key to access to a campaign was my ability to do something for the candidate. My interest in writing about the campaign was flattering and gave the candidate a reason to encourage his staff to cooperate with me. "Come along, pal," said one ultimately victorious candidate to me, "but you be sure to treat us nice in your book:"

Second, my subjects cared greatly that I would not have any 
influence on the course of campaign events or on the election. I found that it was crucial for me to emphasize that nothing I said or did would influence the election. In this, I was following what sociologist William Foote Whyte (1981) calls the cardinal rule of participant observation research-at all costs, actively avoid influencing events (336).

Once, pleased that a television reporter wanted to interview me about the campaign I was observing, I allowed the lights and microphone to be set up around me at a campaign event. I backed out, embarrassing myself just after the camera went on, Whyte's admonition ringing in my ears. Although $I$ was under no illusion that I would affect the voting with an appearance on the evening news in Greenville, it was crucial to convince others that I would not and could not influence events. The interview could have undermined my efforts. I also took great pains to note that my book would not be published for several years, a reassuring fact to people whose time horizons were measured in weeks.

Reveal your purpose, suppress your opinions. To further facilitate trust, I found it best to be completely open about my purpose and tactics. In most cases, this was very easy to do as people were rarely deeply interested in me. Most were satisfied with my business card and with the explanation that I was writing a book on southern congressional elections. Very few people asked me what the point of the book was going to be.

I also revealed that I had spent time with or expected to spend time with the opposition. Even Fenno (1990), on the rare occasion he visited a political opponent of one of his subjects, struggled with the question of whether or not to be open about meeting with both sides. He reluctantly did so and was relieved that it did not appear to matter to those he was talking with (72-73). In my experience, it was not just that it did not matter. Letting people know whom I had talked with, and making a point of not revealing what they had said to me, inspired trust. I believe that being openly tight-lipped about the other side assured my subjects that I would be equally careful about them.

Although it worked best to be as open as possible about purpose and tactics, I was careful to keep my opinions to myself. This did not mean that $I$ could not offer a compliment or two, particularly about the craft of campaign management ("Putting that empty chair next to the candidate at the high school [to emphasize that the opponent refused to debate] was sure clever, Ron."). But it made sense not to advertise my partisanship nor where I stood on the various issues being debated in the campaign. If asked, my ready response was, "I'm an analyst, not an advocate." In fact, few asked. I believe that the good researcher will find that those encountered will often assume that the researcher is sympathetic. On only one occasion did I have to deal with someone who assumed otherwise. In that case, I was asked to leave a Republican meeting because someone "sensed" that I was a Democrat.

Occasionally, the assumption that I was sympathetic led to uncomfortable situations. In one instance, I spent a couple of hours driving around with a white campaign official to various stops in a "campaign caravan." When, out of the blue, he told me a virulently racist joke, I was confronted by an ethical dilemma. Hammer and Wildavsky (1989) advise the interviewer to exercise discipline in such cases and to "withhold judgment on the views of the respondent" (73), but this situation did not quite fall under their scenario for it required a response. Silence, interpreted in other situations as approval, was disapproval in this one. I could not bring myself to laugh but instead responded "That's terrible," as if it were the corniness of the joke and not its message that kept me from laughing. It was an instantaneous reaction, one that came after many days avoiding any confrontation and developing rapport with people, and it was effective from the perspective of my research. Although it was not the most honest moment in my life, $\mathbf{I}$ did not endanger my relationship to him. His comment, and many others that morning, were revealing and important to me.

Don't overlook detail in the rush of activity. When I first went to Alabama and Mississippi, I spent a great deal of time concerned with campaign issues, particularly those covered in the press. This was important, but over time I found that the most interesting material gathered in the field was the detail, the small things that happened that shed light on bigger problems and issues encountered by Republicans and Democrats in the South. When a Mississippi Democrat held a televised press conference at an army base and found a picture of President Bush hanging over his shoulder, his solution to this quandary gave much insight into how he planned to position himself vis-avis the very popular Republican president (his staff took the picture down before the cameras rolled). In Alabama, when a Republican press release charged that the Democratic candidate had been a longhaired professor who taught against the war "while our boys were dying in the rice patties (sic) of Viet Nam," it said as much about the sloppiness of the campaign as the potency of the issue. When a band at a Mississippi Delta Democratic rally improvised a song warning people to avoid Republicans offering money for votes ("If they put a little honey in your hand, tell' $m$ to take their business to someone else"), it spoke volumes about how broad the concern with fraud and vote buying was in the heavily black district.

The point, of course, is that campaign politics is not just about the big issues and the campaign messages that are captured in the newspapers. Important insight comes in gathering observations about the small but very significant decisions, words, events, and quandaries that make up the campaign. The comparative advantage of the social scientist over the reporter is that the social scientist has the luxury of looking for these details and generating some meaning from them. 
The other methodological point here is that studying events as they unfold is not an easy matter. Analyzing campaigns and elections with data collected in the field requires being attentive even to things that may not appear that important at first glance. In the field, it is difficult to sort out what detail is important from what is not, especially as one is working without knowledge of the end result. This calls for energy and vigilance in observing and recording as much detail as possible.

Be a pack rat. I found it helped to take whatever was offered me. Whether it was campaign literature and position papers, press releases, polling information, or editorials clipped from the newspaper, I put it into my briefcase. There were two reasons to actively accumulate all the paraphernalia of the campaign. First, I never knew what might prove useful later, as I was thinking about and writing up my material. Perhaps more important, the act of accepting their propaganda was almost always interpreted positively by the campaigns, a sign that I was actively interested in what they were doing and even sympathetic to their cause. And asking for such material was even more effective in generating goodwill.

$I$ also bought a newspaper in every town I visited, sometimes collecting three or four a day. Back home, it was good to know what other things were going on in the district at the time of the election. Such events set the context for the election, context that was easily forgotten later. Sometimes a letter to the editor or an editorial cartoon proved enlightening. Occasionally there was local color to absorb (in Mississippi cotton country, a swirling controversy around Senator Trent Lott's wife modelling polyester at a charity fashion show). Finally, newspapers representing different parts of the district or serving different minority communities often offered different perspectives on the same events or circumstances, perspectives that otherwise were difficult to get.

Five days before the election on the coast of Mississippi, Hurricane Jerry developed in the Gulf of Mexico. The probability of it hitting Biloxi and Gulfport over the weekend was great, and, having been devastated by Hurricane Camille some 25 years before, residents of the coast prepared for the worst. Also of concern to me, Jerry threatened the election I was covering. The night before it was due to hit, I was at a television station watching the taping of a debate. The meteorologist at the station advised me to have my car packed and ready to go on a moment's notice, as the hurricane was expected to lurch toward the coast by morning. It did not happen. Instead, over the course of the night, the hurricane split in two. Half of it moved west toward Texas, the other half east to Florida. The coast was spared, and so was my research.

Is there another lesson in this story? Maybe not. But perhaps it serves as a parable. The challenge of watching campaigns, more than anything, is dealing with uncertainty. It means adjusting to new circumstances, to others' everchanging plans, to spontaneous opportunities, to surprisingly hostile (or friendly) subjects, and even to acts of nature.

For me, the most difficult uncertainty was the almost excruciating anxiety attached to choosing my cases and waiting to see if they would yield something interesting. My research was not about reconstructing past events and dealing with a known outcome. Time, money, and my connections had to be spent before I knew the final results or the course of events.

Several of the lessons I discuss here-leaving open schedules and arranging interviews creativelydeal with the issue of surviving uncertainty and indeed taking advantage of the fluid nature of the political campaign. The advice to diligently collect campaign material and local newspapers and to gather detail is directed at the need to have material on everything as it is impossible to predict the outcome of events or what will prove to be the crucial moment, circumstance, or detail to explain that outcome. Only in retrospect is it possible to know. And that can be rather intimidating.

Interestingly, it was not just the hurricane that I avoided that week in Mississippi. I missed another disaster the following Tuesday as an earthquake-the "World Series earthquake"-rocked my Oakland, California, home. For me, the meaning of that event is clear. For all the risk involved in participantobservation research, staying home and not doing it was also risky.

\section{Notes}

1. My thanks to Jeffrey Berry and Jonathan Krasno for reading an earlier draft of this piece. Their advice was smart and very helpful to me.

\section{References}

Fenno, Jr., Richard F. 1990. Watching Politicians: Essays on Participant Observation. Berkeley, CA: IGS Press.

Glaser, James M. 1996. Race, Campaign Politics, and the Realignment in the South. New Haven: Yale University Press.

Hammer, Dean, and Aaron Wildavsky. 1989. "The Open-Ended, Semistructured Interview: An (Almost) Operational Guide," in Craftways: On the Organization of Scholarly Work. Aaron Wildavsky, ed. New Brunswick, NJ: Transaction Publishers.

Simon, Herbert. 1985. "Human Nature in Politics: The Dialogue of Psychology with Political Science." American Political Science Review, 79:293-304.

Whyte, William Foote. 1981. Street Corner Society: The Social Structure of an Italian Slum. 3d ed. Chicago: University of Chicago Press.

\footnotetext{
About the Author

James M. Glaser is assistant professor of political science at Tufts University. He is the author of Race, Campaign Politics, and the Realignment in the South, recently published by Yale University Press, and various articles in such journals as British Journal of Political Science, Journal of Politics, and Political Behavior.
} 